\section{DISCUSSION}

To the best of our knowledge, this is the first case report of a TAAA repair in a patient with a GEA graft for coronary artery revascularization. The GEA has been widely used as a graft for $\mathrm{CABG}$, especially for right coronary artery revascularization. In this case, the GEA and radial artery were used in a composite Y-graft to revascularize the right and left coronary arteries. The TAAA was not identified at the time of CABG. We suggest that both the ascending aorta and TAAA should be screened for atherosclerosis or aneurysmal change, via computed tomography, before the GEA is used for CABG. If TAAA is detected by preoperative computed tomography, separate or combined operations can be considered. Recently, Attaran and associates ${ }^{2}$ reported 2 successful cases of combined TAAA repair and $\mathrm{CABG}$.

In this case, we used partial CPB for TAAA repair. Celiac artery flow rate was determined before CPB using duplex scanning. Close monitoring for cardiac ischemia was performed using electrocardiography and transesophageal echocardiography. Hypothermic circulatory arrest can also be considered for TAAA repair, ${ }^{3-5}$ which has the advantage of making sequential aortic clamping and separate perfusion of the visceral arteries unnecessary. This may be a feasible alternative for cases such as the one presented for surgeons who routinely use hypothermic circulatory arrest.

In conclusion, TAAA repair can be safely performed in a patient with a patent GEA graft used for CABG using partial CPB. Duplex scanning was useful to determine celiac artery flow rate in this case.

\section{References}

1. Suzuki T, Asai T, Matsubayashi K, Kambara A, Kinoshita T, Takashima N, et al. In off-pump surgery, skeletonized gastroepiploic artery is superior to saphenous vein in patients with bilateral internal thoracic arterial grafts. Ann Thorac Surg. 2011; 91:1159-64.

2. Attaran S, Field M, Kuduvalli M, Oo A. A combined procedure of thoracoabdominal aortic aneurysm repair and coronary artery bypass grafting: report of two cases. J Thorac Cardiovasc Surg. 2011;141:1078-9.

3. Kulik A, Castner CF, Kouchoukos NT. Outcomes after thoracoabdominal aortic aneurysm repair with hypothermic circulatory arrest. $J$ Thorac Cardiovasc Surg. 2011;141:953-60.

4. Fehrenbacher JW, Siderys H, Terry C, Kuhn J, Corvera JS. Early and late results of descending thoracic and thoracoabdominal aortic aneurysm open repair with deep hypothermia and circulatory arrest. J Thorac Cardiovasc Surg. 2010;140: S154-60.

5. Kouchoukos NT, Masetti P, Rokkas CK, Murphy SF. Hypothermic cardiopulmonary bypass and circulatory arrest for operations on the descending thoracic and thoracoabdominal aorta. Ann Thorac Surg. 2002;74:S1885-7.

\title{
A new type of aortic arch interruption without significant patent ductus arteriosus and with no ventricular septal defect
}

\author{
Alexandre Cazavet, MD, Pierre-Emmanuel Seguela, MD, Philippe Acar, MD, PhD, and \\ Bertrand Leobon, MD, PhD, Toulouse, France
}

We report the case of an infant with a previously unrecorded type of aortic arch interruption (AAI). There was only insignificant patent ductus arteriosus and no ventricular septal defect. Although this congenital heart condition did not fall within the type B1 classification, it may have had the same underlying genetic cause.

\footnotetext{
From the Department of Pediatric Cardiology and Pediatric Cardiovascular Surgery, University Children Hospital of Purpan, Toulouse, France.

Disclosures: Authors have nothing to disclose with regard to commercial support.

Received for publication June 11, 2011; accepted for publication June 28, 2011; available ahead of print July 28, 2011.

Address for reprints: Bertrand Leobon, MD, PhD, Department of Pediatric Cardiology \& Pediatric Cardiovascular Surgery, University Children Hospital of Purpan, 330, Avenue de Grande Bretagne, TSA 70034, 31059 Toulouse Cedex 9, France (E-mail: leobon.b@chu-toulouse.fr).

J Thorac Cardiovasc Surg 2012;143:237-9

$0022-5223 / \$ 36.00$

Copyright (c) 2012 by The American Association for Thoracic Surgery doi:10.1016/j.jtcvs.2011.06.031
}

\section{CLINICAL SUMMARY}

A 2.5-month-old girl was referred to our hospital for collapses and cardiac murmur. She had normal height and weight development, and physical examination revealed only a low systolic murmur.

Two-dimensional echocardiography showed an AAI with a small patent ductus arteriosus of $2 \mathrm{~mm}$, no ventricular septal defect, and an atrial septal defect of $4 \mathrm{~mm}$. It also showed a left ventricular hypertrophy but without left ventricular outflow tract obstruction. Electroencephalography and brain magnetic resonance imaging (with a complete Willis circle) were normal. Both 2- and 3-dimensional computed tomographic scan angiography (Figure 1, $A, B$, and $C$ ) established the diagnosis. The ascending aorta gave rise to both carotid arteries, and the descending aorta was supplied by large subclavian arteries supplemented by collaterals between external carotids and vertebral arteries. The right subclavian artery was retroesophageal; however, bronchoscopy and esophageal opacification showed no significant 


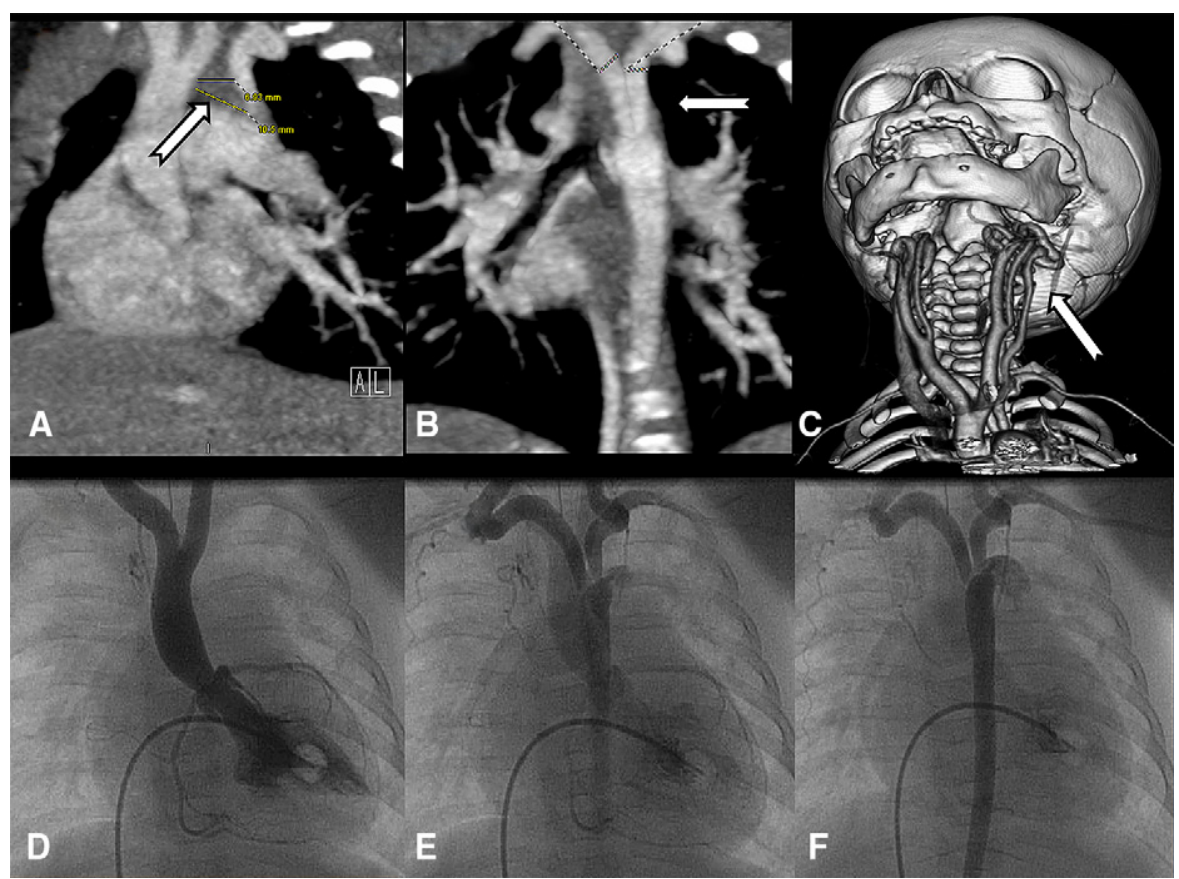

FIGURE 1. Two-dimensional scan frontal reconstructed images showing the aortic arch interruption (arrows), the ascending aorta giving both carotid arteries (A) and both subclavian arteries supplying the descending aorta (B). Three-dimensional angiographic scan reconstructed image showing large external carotid arteries and large collaterals (C, arrow) to vertebral arteries. Cardiac catheterization showing the previously described anatomy at 3 different times (D, E, and F).

narrowing. Cardiac catheterization (Figure 1, $D, E$, and $F$ ) confirmed the described anatomy and pathophysiology. We measured a gradient of $45 \mathrm{~mm} \mathrm{Hg}$ between the ascending and descending aorta, confirming the indication for surgical repair.

Through a sternotomy, after ligation and section of a small patent ductus arteriosus (with no hemodynamic change) and an extensive dissection of supra-aortic vessels and descending aorta, a direct aortoaortic anastomosis was achieved under double partial lateral clamping (Figure 2, $A$ and $B$ ). Cardiopulmonary bypass was available on standby but was not required with this peculiar anatomy, because lateral clamping preserved the perfusion of carotid arteries, cervical anastomosis, and descending aorta. During surgery, the absence of thymus was noted. Chromosome 22q11 deletion syndrome was confirmed by genetic analysis.

The postoperative course and follow-up at 3, 6, and 12 months were satisfactory with no significant residual gradient, regression of left ventricular hypertrophy. Computed tomographic scan control shows a good result (Figure 2, C).

\section{DISCUSSION}

The child was symptom free, but we could not assess the pressure in the left ventricle and ascending aorta because all the peripheral arteries (except the carotids) were downstream the cervical anastomosis. To confirm indication for a surgical repair, we assessed the left ventricular pressure by cardiac catheterization through the foramen ovale. This examination confirmed high left ventricular pressures, with the potential for left ventricular failure or neurologic complications.

With respect to anatomic features, an AAI is usually associated with a large patent ductus arteriosus, which is crucial in supplying blood flow to the descending aorta, and a ventricular septal defect is associated in 2 thirds of cases. ${ }^{1}$ The descending aorta of our patient was perfused by vertebral arteries through large collaterals developed from external carotid arteries. The lesion in our patient thus cannot be classified as a type B1 AAI according to Celoria's revised classification ${ }^{2}$ because of the absence of a significant patent ductus arteriosus. This unique AAI may have resulted, however, like most $(60 \%)$ classic type B AAIs, from an abnormal sequence of development in the embryonic pharyngeal system related to chromosome $22 \mathrm{q} 11$ deletion syndrome. ${ }^{3}$

Finally, this atypical presentation of IAA allowed us to perform a direct aortoaortic anastomosis to restore a physiologic circulation without cardiopulmonary bypass or interposition of any vascular graft. 

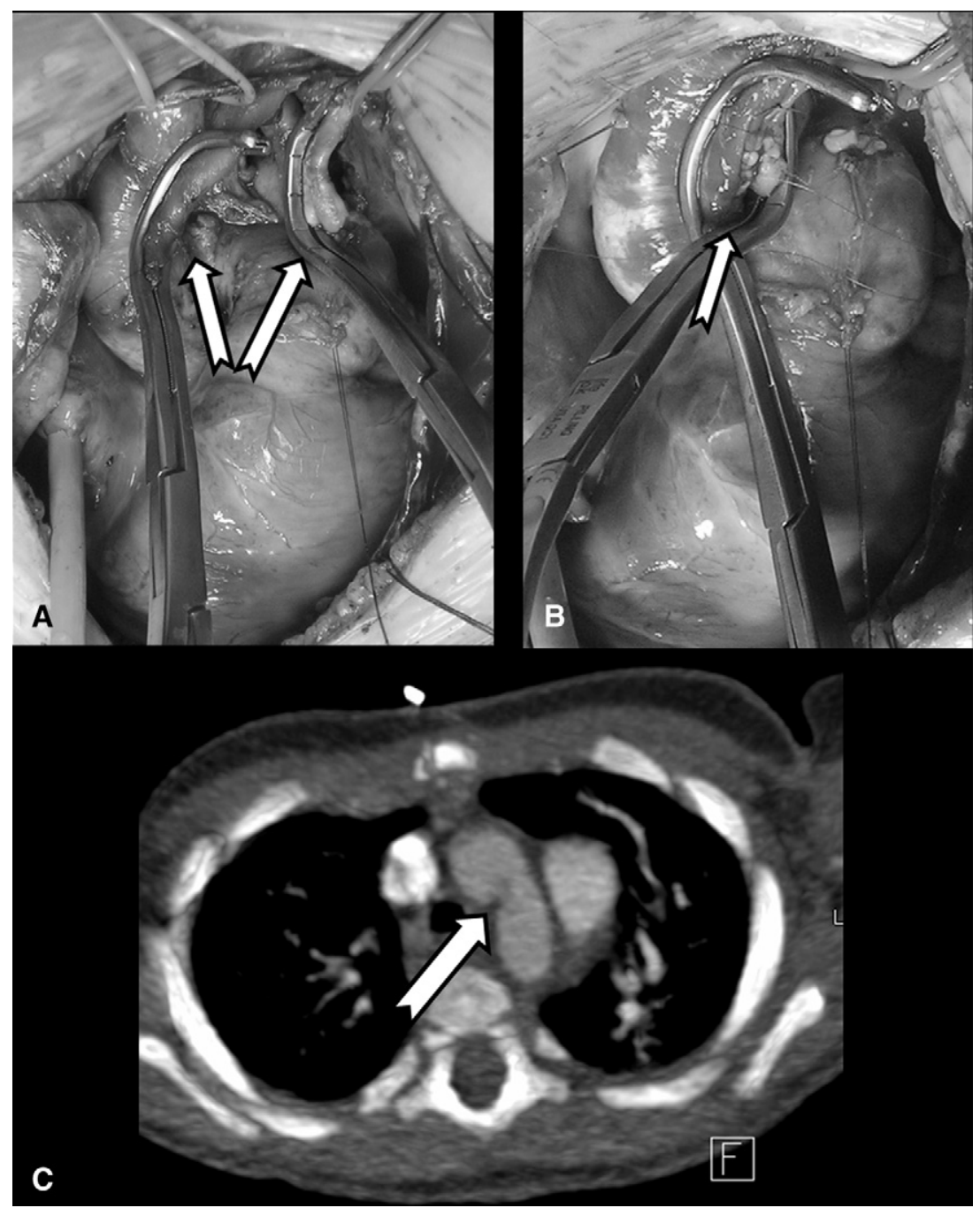

FIGURE 2. Intraoperative images showing the double partial lateral clamping (A, arrows) and the direct anastomosis (B, arrow). Six-month follow-up angiographic scan showing the reconstructed aortic arch (C, arrow).

\section{References}

1. McCrindle BW, Tchervenkov CI, Konstantinov IE, Williams WG, Neirotti RA, Jacobs ML, et al. Risk factors associated with mortality and interventions in 472 neonates with interrupted aortic arch: a Congenital Heart Surgeons Society study. J Thorac Cardiovasc Surg. 2005;129:343-50.
2. Oppenheimer-Dekker A, Gittenberger-de Groot AC, Roozendaal H. The ductus arteriosus and associated cardiac anomalies in interruption of the aortic arch. $P e$ diatr Cardiol. 1982;2:185-93.

3. Momma K. Cardiovascular anomalies associated with chromosome 22q11.2 deletion syndrome. Am J Cardiol. 2010;105:1617-24. 